\title{
ESTUDO SOBRE AS MUDANÇAS CLIMÁTICAS NOS ÚLTIMOS ANOS DA EDUCAÇÃO BÁSICA EM JABOTICABAL (SP)
}

\author{
Fernanda de Freitas Borges ${ }^{1}$ \\ Fernando Antonio Bataghin ${ }^{2}$ \\ Tiffani Velasco de Oliveira ${ }^{3}$
}

\begin{abstract}
Resumo: O objetivo do estudo foi avaliar o conhecimento dos alunos dos últimos anos da educação básica, no município de Jaboticabal (São Paulo), sobre as mudanças climáticas. O estudo revelou que mais da metade dos estudantes dos anos finais do ensino fundamental e médio, possuem conhecimento sobre o aquecimento global; acreditam que o desmatamento pode contribuir para as mudanças climáticas; que o efeito estufa pode ser aumentado pelas ações do homem; que é importante debater a problemática no cenário atual e que a população pode contribuir a favor do clima. No entanto, ambos os grupos desconhecem os ODS e avaliam como regular a abordagem do tema na escola. Portanto, concluiu-se que o ambiente escolar tem um papel fundamental na formação de alunos conscientes e abordar esta problemática é de suma importância para a formação dos cidadãos sobre as questões ambientais, as quais suas ações poderão influenciar nas condições de vida no planeta.
\end{abstract}

Palavras-chave: Educação Básica; Mudanças Climáticas; Sensibilização Ambiental.

Abstract: The aim of the study was to evaluate the knowledge of students of the last years of basic education, in the Jaboticabal (São Paulo, Brazil), about climate change. The study revealed that more than half of the students in the final years of elementary and high school have knowledge about global warming; believing that deforestation can contribute to climate change; that the greenhouse effect can be increased by the actions of man; that it is important to debate the issue in the current scenario and that the population can contribute to the climate. However, both groups are unaware of the SDG and the assessment of how to regulate the approach to the topic at school. Therefore, it was concluded that the school environment has a fundamental role in the formation of conscientious students and addressing this issue is of paramount importance for the education of citizens on environmental issues, such as what their actions affect the conditions of life on the planet.

Keywords: Basic Education; Climate Changes; Environmental Sensibilization.

1 Faculdade Nilo De Stéfani. E-mail: ferfreitasborges@gmail.com,

Link para o Lattes: http://lattes.cnpq.br/5315488595574139

2 Faculdade Nilo De Stéfani. E-mail: bataghin@gmail.com,

Link para o Lattes: http://lattes.cnpq.br/1364436595052131

${ }^{3}$ Faculdade Nilo De Stéfani. E-mail: tiffani_velasco@hotmail.com,

Link para o Lattes: http://lattes.cnpq.br/60911999314799783 


\section{Introdução}

A grande preocupação dos pesquisadores com as mudanças climáticas diz respeito à capacidade de suporte do planeta Terra diante das alterações causadas por ações antrópicas, visto que os estudos demonstram que o planeta está entrando em colapso e que necessita de ações urgentes para evitar uma catástrofe e extinção em massa de espécies, afetando a própria sobrevivência humana.

Segundo o naturalista britânico David Attenborough, as mudanças climáticas podem nos afetar de diversas maneiras; como escassez de água doce, diminuição da produção de alimentos em todo o mundo causando desnutrição, aumento de doenças de veiculação hídrica e malária, inundações, secas, aumento do nível do mar devido ao derretimento das geleiras, acidificação dos oceanos devido a maior absorção de gás carbônico, eventos climáticos extremos, ondas de calor e extinção de animais e plantas (BBC, 2019).

As mudanças do clima são uma ameaça a biodiversidade das florestas, colocando em risco os serviços ambientais prestados aos seres humanos. As florestas tropicais, como a Amazônica, tendem a ser mais vulneráveis a estas mudanças (FEARNSIDE, 2008). A emissão de gases de efeito estufa (dióxido de carbono, metano e óxido nitroso) estão relacionadas a diversas atividades antrópicas, como queimadas, criação de bovinos e agricultura. Estas emissões contribuem para as mudanças climáticas, sendo previstos impactos significativos para os próximos 100 anos (NOBRE, 2001).

O desmatamento é a principal fonte de emissões de gases de efeito estufa (GEE) no Brasil, sendo a maior parte destinada a pastagem. Com isso, o carbono é liberado para atmosfera na forma de gás carbônico e metano. Além de que as queimadas, utilizadas após a derrubada das árvores para a exploração madeireira, também liberam carbono, contribuindo ainda mais para o aquecimento global. As florestas amazônicas têm um importante papel na mitigação do aquecimento global devido ao seu grande estoque de carbono na biomassa e no solo (FEARNSIDE, 2009).

Diminuir as emissões de GEE é importante para a própria sobrevivência. O ser humano depende do ecossistema em que está inserido e, se continuar no ritmo atual de destruição da natureza, sua existência estará em risco. Globalmente, pode-se perceber a necessidade da preservação e recuperação do meio ambiente, resultantes de danos causados por ações antrópicas (BOTH; FISCHER, 2017).

Programas educativos que abordam temas da diversidade regional, no caso do Brasil, que apresenta ecossistemas diversificados e complexos, apontam que cada vez mais os comportamentos, valores e atitudes sustentáveis tem sido estimulado. Em adição, este estímulo ocorre de acordo com cada prioridade na zona da educação formal e informal, mediante a educação em diferentes estágios, colaborando para atingir a meta do 
desenvolvimento sustentável (GUERRA et al., 2010). Sendo assim, contribuir para diminuição de poluentes derivados de ações antrópicas (ações promovidas pelos seres humanos que afetam direta ou indiretamente o meio ambiente) que promovem o aquecimento global e as mudanças climáticas pode ser uma ação educativa. Partindo deste princípio, é importante lidar com a problematização e discussão sobre estas mudanças, quais são suas causas e, também, o quanto a futura geração está pronta para enfrentar os impactos negativos delas.

A necessidade de se abordar o tema surgiu devido aos fatores climáticos observados na atualidade. O planeta Terra está em constante mudança, e não seria diferente para o clima, principalmente quando é alterado pelas ações antrópicas que, a médio ou longo prazos, afetará as vidas de maneira mais significativa e, atualmente, já é possível sentir suas consequências. Esta pesquisa trouxe a perspectiva do público-alvo em relação as mudanças climáticas, analisou o entendimento dos alunos e como o assunto está sendo abordado nas escolas. Ainda, avaliou o quão informado os alunos estão sobre os impactos que as mudanças climáticas podem gerar e qual a percepção e expectativas de cada um.

Nesse sentido, o objetivo deste trabalho foi avaliar o conhecimento dos alunos dos últimos anos do ensino fundamental e médio nas escolas de Jaboticabal, estado de São Paulo, Brasil. Estes alunos representam uma parcela das pessoas que vivenciarão os impactos das mudanças no clima a médio e longo prazos, o que os tornam agentes de transformação local e difusores de informações.

\section{Linha do tempo das mudanças climáticas e efeitos a curto, médio e longo prazo nas populações}

As variações de temperaturas no globo terrestre são observadas desde o ano de 1850. Entre os anos de 1920 a 1946, notou- um aumento de aproximadamente $0,4^{\circ} \mathrm{C}$, período que corresponde ao final da Segunda Revolução Industrial. A relação média da temperatura no período de 1961 e1990 aumentou em aproximadamente $0,7^{\circ} \mathrm{C}$ (MOLION, 2008) e atualmente 0 aumento da temperatura global está em cerca de $1^{\circ} \mathrm{C}$, com a previsão de chegar, entre 2020 a 2024 , a $1,15^{\circ} \mathrm{C}-1,46^{\circ} \mathrm{C}$, resultando em um recorde anual de aquecimento (HODGES, 2020). O primeiro período de aquecimento provavelmente foi ocasionado por causas naturais, possivelmente acarretada pelo aumento da produção de energia solar e a redução de albedo planetário (IPCC, 2018). Este fenômeno representa a fração refletida da energia radiante do sol, que incide sobre a Terra, sendo aproximadamente $30 \%$ refletida de volta ao espaço (VEISSID; PEREIRA, 2000).

Antes do final da Segunda Guerra Mundial, as ações antrópicas emitiam cerca de $6 \%$ dos níveis atuais (MOLION, 2008). O dióxido de carbono $\left(\mathrm{CO}_{2}\right)$ é o GEE de origem antrópica mais relevante e sua concentração global 
na atmosfera aumentou de um valor pré-industrial para larga escala. Avaliando a tendência do aquecimento global de longo prazo, desde o período mencionado, a temperatura média global para o intervalo de 2006-2015 aumentou $0,87^{\circ} \mathrm{C}$, sendo mais alta que a média registrada entre o período de 1850-1900. Atualmente, o aquecimento global antrópico aumenta cerca de $0,2^{\circ} \mathrm{C}$ por década (IPCC, 2018).

As emissões anuais de dióxido de carbono, derivados da combustão de combustíveis fósseis, demonstram relação direta com fatores como: aumento populacional, intensidade energética e o PIB (produto interno bruto). A cada década que se passa, podemos perceber um aumento significativo da população, do uso de energias e combustíveis fosseis (STECKEL et al. 2011). Para Alvares Junior (2012), existe uma necessidade urgente de determinar estratégias para estabelecer limites as emissões de $\mathrm{CO}_{2}$ por meio de uma economia eficiente, conservação de energia, uso de energias renováveis e diminuição no uso de combustíveis fósseis.

Em 2018, o IPCC divulgou um relatório com os impactos do aquecimento global, com aumento máximo de temperatura de $1,5^{\circ} \mathrm{C}$ acima dos níveis pré-industriais e as respectivas trajetórias de emissão de GEE, de acordo com a decisão da $21^{\text {a }}$ Conferência das Partes da Convenção Quatro das Nações Unidas sobre Mudanças do Clima, para adoção do Acordo de Paris. Sobre o aquecimento causado por emissões antrópicas desde o período pré-industrial até o presente, estima-se que persistirá por séculos e milênios e continuará causando mudanças a longo prazo no sistema climático, como o aumento dos níveis dos oceanos. Prevê que os riscos referentes ao clima para a saúde, segurança alimentar, meios de subsistência e segurança humana, abastecimento de água e crescimento econômico aumentem com o aquecimento global de $1,5^{\circ} \mathrm{C}$ e aumentem ainda mais com $2^{\circ} \mathrm{C}$ (IPCC, 2018).

Outro relatório, denominado "Oceano e a Criosfera em Clima de Mudança", compila as principais conclusões sobre os impactos, mudanças e riscos projetados das mudanças climáticas sobre o oceano e a camada de gelo permanente da Terra. Nas últimas décadas, o aquecimento global trouxe o encolhimento generalizado da Criosfera, os mantos de gelo e geleiras em todo o planeta perderam massa, principalmente devido ao derretimento da superfície. Em meados do século 20, devido à redução da Criosfera, a segurança alimentar e hídrica foi impactada negativamente em muitas regiões, prejudicando o acesso e disponibilidade de alimentos. Afetando também a saúde humana, com o aumento do risco de doenças transmitidas por alimentos e água, desnutrição, dentre outros. Além disso, as comunidades costeiras ficaram expostas a vários perigos relacionados ao clima, incluindo ciclones tropicais e inundações (IPCC, 2019). 


\section{Ações mundiais em prol do clima e Objetivos de Desenvolvimento Sustentável}

A atuação dos países na criação de ações globais, que tem por objetivo o desenvolvimento sustentável e a preservação do meio ambiente, são de suma importância e relevância. Logo após a Revolução Industrial, o cenário dos impactos ambientais se intensificou, em virtude da evolução tecnológica e aumento na produção. Diminuir a emissão de poluentes, proteger a natureza, combater a fome e a desigualdade, reduzir os resíduos e apoiar economias sustentáveis são metas essenciais para atuações mundiais.

Dois tratados internacionais sobre o clima definem metas de reduções de emissões e objetivos de minimizar as consequências do aquecimento global, o Protocolo de Kyoto e o Acordo de Paris. O Protocolo de Kyoto foi criado em 1997, mas entrou em vigor apenas em 2005, logo após o atendimento às condições que exigiam a ratificação por, no mínimo, $55 \%$ do total de países-membros da Convenção e que fossem responsáveis por, pelo menos, 55\% do total das emissões de 1990 (MCT, 2020). Entre 2008 e 2012, primeiro período de compromisso, os países industrializados e a Comunidade Europeia assumiram o compromisso de reduzir as emissões de GEE para uma média de 5\% em relação aos níveis de 1990. Já no segundo período de compromisso, as Partes se comprometeram a reduzir as emissões em pelo menos 18\% em um período de oito anos, entre 2013 a 2020. Cada país negociou a sua própria meta de redução de emissões em função da sua visão sobre a capacidade de atingi-la no período considerado. Mesmo estando entre os principais emissores de gases de efeito estufa, os Estados Unidos não ratificaram o Protocolo de Kyoto, contudo, continuaram com as obrigações e responsabilidades definidas pela Convecção. O Brasil ratificou o documento em 2002 com o Decreto Legislativo o 144 de 2002 (BRASIL, 2002) e, posteriormente, instituiu a Política Nacional sobre Mudança do Clima (PNMC) (BRASIL, 2009) e, a partir daí, definiu estratégias e políticas relacionadas ao monitoramento e à implementação de planos setoriais de mitigação e adaptação através do Ministério do Meio Ambiente.

O tratado internacional sobre o clima mais recente é o Acordo de Paris, criado em 2015, é um compromisso discutido entre 195 países, com o objetivo de minimizar as consequências do aquecimento global, mantendo a temperatura média global abaixo de $2^{\circ} \mathrm{C}$ em relação aos níveis pré-industriais, desenvolvimento de baixas emissões de GEE, entre outros. Para entrar em vigor, em 2016, precisou da ratificação de pelo menos 55 países responsáveis por $55 \%$ das emissões globais de gases de efeito estufa (MPF, 2020). Os países participantes se comprometeram em reduzir as emissões, mas em 2017 os Estados Unidos saíram do acordo, causando preocupação, pois é um dos maiores poluidores do planeta. O Brasil concluiu sua ratificação em 2016 e suas principais metas são: até 2025 reduzir as emissões de GEE em 37\% abaixo dos níveis de 2005 e até 2030 reduzir em 43\%; aumentar a participação de biocombustíveis em 18\%; transformar $45 \%$ da matriz energética por 
energias renováveis; zerar o desmatamento ilegal na Amazônia e reflorestar 15 milhões de hectares de pastagens (MPF, 2020).

Com o intuito de alcançar a sustentabilidade, no ano de 2000, na sede das Nações Unidas, líderes de 189 países se encontraram na cidade de Nova York para aprovarem a Declaração do Milênio, a qual se consiste em um compromisso de trabalharem em conjunto na construção de um mundo mais seguro, próspero e justo. A declaração estabeleceu oito metas (Figura 1) a serem atingidas até 2015, conhecidas como Objetivos de Desenvolvimento do Milênio (ODM) (PLATAFORMA AGENDA 2030, 2020).

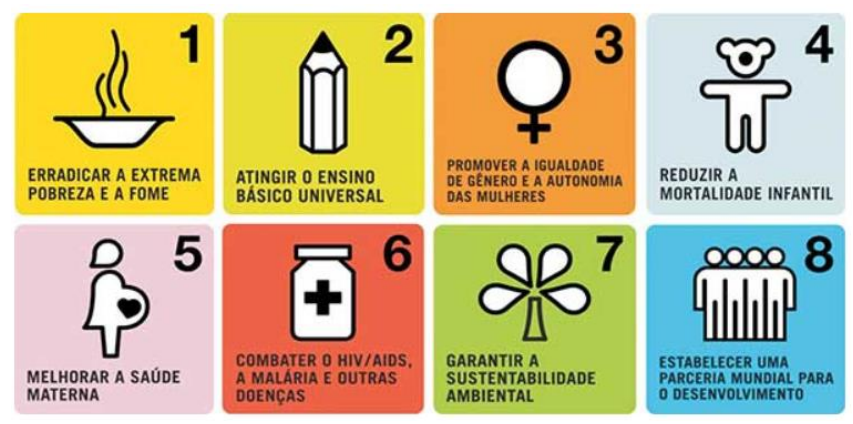

Figura 1: Objetivos de Desenvolvimento do Milênio.

Fonte: Plataforma Agenda 2030 (2020).

Baseado nos ODM, foram criados os 17 Objetivos de Desenvolvimento Sustentável (ODS), os quais devem ser implementados por todos os países do mundo nos próximos 15 anos, até o ano de 2030, buscando fortalecer a paz universal (Figura 2).

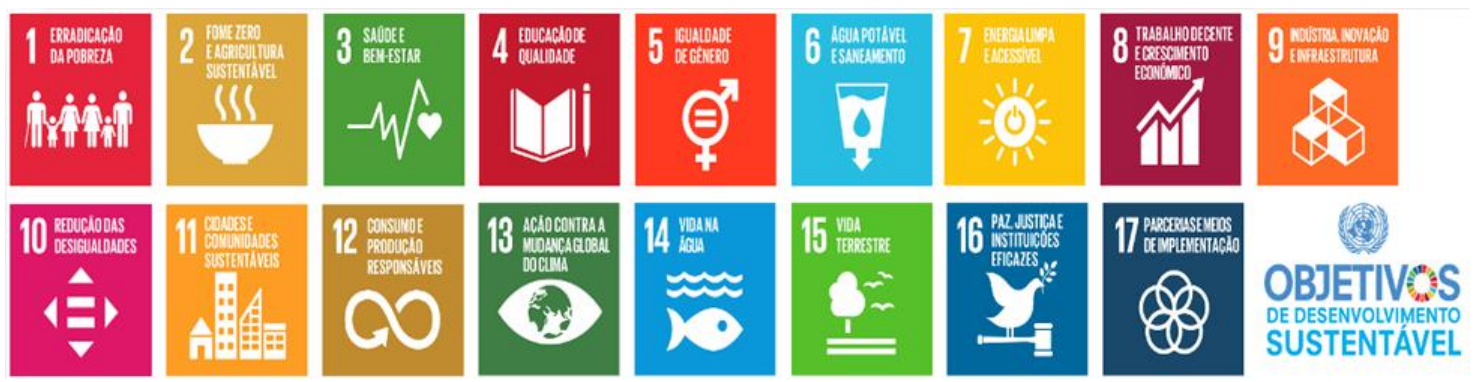

Figura 2: Objetivos do Desenvolvimento Sustentável.

Fonte: Plataforma Agenda 2030 (2020).

A Agenda 2030, como é conhecida, além de universal, constitui um plano de ação realizado para as pessoas, o planeta e para a prosperidade, com o propósito de promover a paz e incentivar a parceria global. Conta com 17 objetivos e 169 metas, criados a partir dos ODM que não conseguiram ser concluídos. Possui a finalidade de concretizar os direitos humanos de todos, alcançar a igualdade de gênero e o empoderamento das mulheres e meninas, 
entre outros. Equilibram as três dimensões do desenvolvimento sustentável: econômica, social e ambiental (ONU, 2015).

Na agenda, o ODS 13 "Ação contra a mudança global do clima" aborda as medidas urgentes para combater a mudança do clima e seus impactos. As metas abrangem o reforço da resiliência e capacidade de adaptação a riscos e catástrofes naturais (meta 13.1), integrar medidas de mudança do clima nas políticas, estratégias e planejamento nacionais (meta 13.2), melhorar a educação e conscientização sobre mitigação, adaptação e redução de impactos (meta 13.3), implementar o compromisso assumido pelos países desenvolvidos, partes da UNFCCC, para atender as necessidades dos países em desenvolvimento nas ações de mitigação e promover mecanismos para a criação de capacidades para o planejamento e gestão, inclusive com foco em mulheres, jovens, comunidades locais e marginalizados (metas 13.a e 13.b) (ONU, 2015). Alguns indicadores já foram desenvolvidos em cada país e suas metas locais devem ser alinhadas com os respectivos planos de governo municipais.

\section{Contribuições locais como metas de educação ambiental e o papel da educação no desenvolvimento sustentável}

Para o Ministério da Educação (MEC), a Agenda 21 é um instrumento de planejamento para a construção de sociedades sustentáveis, a qual combina métodos de proteção ambiental, eficiência econômica e justiça social, em diferentes bases geográficas. Sendo assim, também podemos contar com a Agenda 21 Brasileira (para o desenvolvimento sustentável do país) e a Agenda 21 Local (implementação em um determinado território) (SECAD, 2007). A elaboração da Agenda 21 nas escolas, além de outras iniciativas, tem disponibilizado espaços de atuação em defesa do meio ambiente e de diálogos, para uma ação positiva tanto nas escolas como no meio familiar e social. A Comissão de Meio Ambiente e Qualidade de Vida nas Escolas (COMVIDA) busca incluir a comunidade escolar no contexto ambiental, dispondo do objetivo de cada escola desenvolver a Agenda 21 Escolar, com um acompanhamento nos projetos de educação ambiental e organizar uma Conferência de Meio Ambiente na Escola (JABOBI et al., 2011). Segundo o autor, existe o interesse do governo federal em qualificar o sistema educacional atribuindo um maior envolvimento com a temática "Mudança Climática", podendo ser executado com a organização de conferências e a produção de materiais didáticos. Todavia, estas iniciativas têm alcances diferentes em cada região do país.

A aprendizagem intergeracional é a interação entre diferentes gerações e pode ocorrer em diferentes contextos, sendo essencial para o aprendizado ao longo da vida tendo como objetivo melhorar os conhecimentos e competências em uma perspectiva social, pessoal e cívica. Acredita-se que à medida que os adolescentes conheçam fatos e informações relacionadas as mudanças climáticas, eles serão menos influenciados por fatores socioideológicos do que 
os adultos. Muitos desses fatores ajudam a ilustrar a falta de preocupação com tais mudanças no clima e a ação coletiva relacionada (LAWSON et al., 2019). Liberdade":

Segundo Freire (1967, p.105), em seu livro “Educação Como Prática da

[ ] acontece, porém, que a toda compreensão de algo corresponde, cedo ou tarde, a uma ação. Captado um desafio, compreendido, admitidas as hipóteses de resposta, o homem age. A natureza da ação corresponde à natureza da compreensão. Se a compreensão é crítica ou preponderantemente crítica, a ação também o será. Se é mágica a compreensão, mágica será a ação.

Desta forma, se possuirmos em nossa sociedade pessoas conscientizadas e que compreendam a importância de se debater as mudanças climáticas, a ação seria positiva e voltada em prol a preservação da natureza, e consequentemente, haveria um maior índice em atividades voltadas para mitigação e redução de problemas provenientes da mudança da temperatura global.

\section{Metodologia}

A pesquisa teve caráter descritivo, do tipo quali-quantitativa e utilizou uma base bibliográfica seguida de levantamento de dados. A pesquisa bibliográfica foi desenvolvida a partir de materiais publicados em diversas fontes. Ela pode ser realizada independentemente ou constituir parte de uma pesquisa descritiva ou experimental. "A pesquisa descritiva estuda e descreve características, propriedades ou relações existentes na comunidade, grupo ou realidade pesquisada" (CERVO; BERVIAN; SILVA, 2007, p.62). Foi realizada uma coleta padronizada de informações, mediante autorização das escolas, com os discentes dos últimos anos do ensino fundamental - EF ( $9^{\circ}$ ano) e ensino médio - EM ( $3^{\circ}$ ano), em escolas públicas e particulares da cidade de Jaboticabal/SP sobre a temática "Mudanças climáticas". Foi realizado um levantamento prévio no município sobre a quantidade de escolas e quais se encaixavam no perfil da pesquisa, respectivas séries da educação. Do total, nove escolas participaram da pesquisa, sendo quatro estaduais, duas municipais e três particulares. De cada uma das escolas, participaram da pesquisa, em média, 24 estudantes do $9^{\circ}$ ano do EF e 11 estudantes do $3^{\circ}$ ano do EM. No total foram entrevistados 318 alunos.

O instrumento de coleta de dados foi um questionário semiestruturado que abordou questões sobre o conhecimento das temáticas relacionadas ao aquecimento global, ações antrópicas e efeito estufa; das relações das queimadas com as atividades agropecuárias e com as emissões de gases do efeito estufa, bem como a relação dos desmatamentos com as mudanças climáticas. Também foram avaliados os graus de satisfação em relação a abordagem do tema nas escolas e quais ações julgam ser importantes para 
conter as mudanças climáticas em âmbitos local e nacional. O questionário socioambiental foi aplicado de forma online na plataforma do Google Forms ${ }^{\circledR}$. Posteriormente, foi realizada uma comparação entre as duas séries para analisar o grau de desenvolvimento da temática. Isso possibilitou a observação do grau de instrução que está sendo transmitido pelas escolas com a abordagem do tema de modo transversal a outras disciplinas. Os resultados foram comparados aos painéis nacionais e internacionais científicos avaliando a amplitude da importância de ações de combate ao aquecimento global e diminuição de impactos locais.

\section{Resultados e discussão}

Dos estudantes do $9^{\circ}$ ano do ensino fundamental avaliados, $76 \%$ tem 14 anos, $64 \%$ pertence ao sexo feminino e $84 \%$ estuda na rede pública. A maioria sabe o que é o aquecimento global e efeito estufa, porém apenas um pouco mais da metade sabe o que é ação antrópica e muitos acreditam que o efeito estufa pode ser aumentado pelas ações do homem. Todos acreditam que o aquecimento global é real e que as mudanças no clima podem influenciar negativamente a vida. A maioria acredita que o desmatamento pode contribuir para as mudanças climáticas e grande parte deles apontaram que $0 \mathrm{CO}_{2}$ é 0 GEE mais abundante da Terra e que as queimadas são a principal fonte de emissão de GEE do Brasil.

Dos alunos do $3^{\circ}$ ano do ensino médio, $91 \%$ tem 17 anos, $75 \%$ pertence ao sexo feminino e $83 \%$ estuda na rede pública. Todos sabem o que é aquecimento global e acreditam que este fenômeno é real e que o desmatamento pode contribuir para as mudanças climáticas, podendo influenciar negativamente a vida. A maioria sabe o que é ação antrópica e efeito estufa e concordam que isso pode ser aumentado pelas ações do homem. Também sabem que o $\mathrm{CO}_{2}$ é o GEE mais abundante da Terra e que as queimadas são a principal fonte de emissão do Brasil. Todos concordam que as ações insustentáveis dos seres humanos são prejudiciais a vida na Terra, reconhecem a importância de debater a problemática no cenário atual e acreditam que a população pode contribuir a favor do clima. A maioria dos alunos concordou que as queimadas na Amazônia e no Pantanal ocorrem devido ao desmatamento para a expansão da agricultura e criação de gado e acredita que as mudanças climáticas são um problema governamental e cerca de metade deles, às vezes, pesquisam algo sobre as mudanças climáticas (Tabela 1). 
Tabela 1: Resultados obtidos na pesquisa sobre mudanças climáticas, com alunos do $9^{\circ}$ ano do ensino fundamental e do $3^{\circ}$ ano do ensino médio, no município de Jaboticabal-SP.

\begin{tabular}{|c|c|c|}
\hline PERGUNTAS & $\begin{array}{l}9^{\circ} \text { ANO DO ENSINO } \\
\text { FUNDAMENTAL }\end{array}$ & $\begin{array}{l}3^{\circ} \text { ANO DO ENSINO } \\
\text { MÉDIO }\end{array}$ \\
\hline Sabem o que é aquecimento global. & $88 \% \operatorname{sim}$ & $100 \% \operatorname{sim}$ \\
\hline Sabem o que é ação antrópica. & $64 \% \operatorname{sim}$ & $75 \% \operatorname{sim}$ \\
\hline Sabem o que é efeito estufa. & $84 \% \operatorname{sim}$ & $91 \% \operatorname{sim}$ \\
\hline $\begin{array}{l}\text { Acreditam que o desmatamento pode } \\
\text { contribuir para as mudanças climáticas. }\end{array}$ & $96 \%$ concordam & $100 \%$ concordam \\
\hline $\begin{array}{l}\text { Acreditam que o aquecimento global é } \\
\text { real. }\end{array}$ & $100 \%$ concordam & $100 \%$ concordam \\
\hline $\begin{array}{l}\text { Acreditam que as mudanças no clima } \\
\text { podem influenciar negativamente a vida. }\end{array}$ & $100 \%$ concordam & $100 \%$ concordam \\
\hline $\begin{array}{l}\text { Acreditam que o efeito estufa pode ser } \\
\text { aumentado pelas ações do homem. }\end{array}$ & $72 \%$ concordam & $83 \%$ concordam \\
\hline $\begin{array}{l}\text { Sabem que } \mathrm{CO}_{2} \text { é o } \\
\text { abundante da Terra. }\end{array}$ & $76 \% \operatorname{sim}$ & $75 \% \operatorname{sim}$ \\
\hline $\begin{array}{l}\text { Sabem que as queimadas são a principal } \\
\text { fonte de emissão de GEE do Brasil. }\end{array}$ & $80 \% \operatorname{sim}$ & $91 \% \operatorname{sim}$ \\
\hline $\begin{array}{l}\text { Acreditam que ações insustentáveis dos } \\
\text { seres humanos, como desmatamentos, } \\
\text { são prejudiciais a vida na Terra. }\end{array}$ & $96 \%$ concordam & $100 \%$ concordam \\
\hline $\begin{array}{l}\text { Acreditam que as queimadas na } \\
\text { Amazônia e no Pantanal ocorrem devido } \\
\text { ao desmatamento para a expansão da } \\
\text { agricultura e criação de gado. }\end{array}$ & $92 \%$ concordam & $92 \%$ concordam \\
\hline $\begin{array}{l}\text { Reconhecem a importância de debater a } \\
\text { problemática no cenário atual. }\end{array}$ & $79 \%$ concordam & $100 \%$ concordam \\
\hline $\begin{array}{l}\text { Acreditam que as mudanças climáticas } \\
\text { são um problema governamental. }\end{array}$ & $72 \%$ concordam & $83 \%$ concordam \\
\hline $\begin{array}{l}\text { Acreditam que a população pode } \\
\text { contribuir a favor do clima. }\end{array}$ & $100 \%$ concordam & $100 \%$ concordam \\
\hline $\begin{array}{l}\text { Pesquisam informações sobre as } \\
\text { mudanças climáticas. }\end{array}$ & $52 \%$ às vezes & $58 \%$ às vezes \\
\hline
\end{tabular}

Fonte: Elaborado pelos autores (2020).

Quase todos os alunos apontaram que ações insustentáveis dos seres humanos, como desmatamentos, são prejudiciais a vida na Terra e que as queimadas na Amazônia e no Pantanal ocorrem devido ao desmatamento para a expansão da agricultura e criação de gado, concordando com a preservação do bioma. A maioria reconheceu a importância de debater a problemática no cenário atual e acreditou que as mudanças climáticas são um problema governamental. Em unanimidade, os alunos acreditam que a população pode contribuir a favor do clima e, cerca de metade dos alunos, às vezes, pesquisam informações sobre as mudanças climáticas.

Porém, quando questionados sobre os ODS, menos da metade conheciam ou já tinham ouvido falar do assunto (Figura 3). 
$9^{\circ}$ ano do ensino fundamental

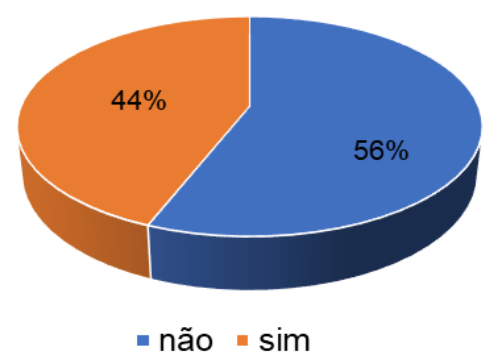

$3^{\circ}$ ano do ensino médio

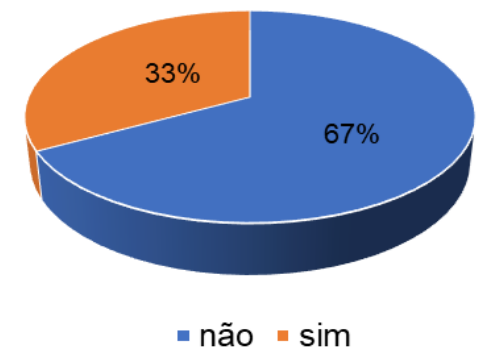

Figura 3: Percentual de alunos dos últimos anos do Ensino Fundamental e Ensino Médio que conhecem os ODS.

Fonte: Elaborado pelos autores (2020).

Estudos apontam que o desmatamento ilegal está ligado a especulação e grilagem de terras públicas na região da Amazônia, contando ainda com a exploração de madeira, garimpo e outras ilegalidades. $O$ desmatamento é a maior fonte de emissão de GEE no Brasil, o que contribui para o aquecimento global, tornando a preservação das florestas essenciais para a conservação dos processos biológicos e climáticos, fornecendo chuvas para irrigar lavouras e abastecer reservatórios, fundamentais para segurança hídrica, energética e alimentar da nação. A meta que o Brasil assumiu em 2016, perante a Convenção do Clima das Nações Unidas, é zerar o desmatamento ilegal no País até 2030. Internamente o Plano Plurianual, que foi aprovado pelo governo federal em 2019, tem como objetivo reduzir o desmatamento e as queimadas ilegais no Brasil em 90\% até 2023 (ESCOBAR, 2020).

Segundo dados do Instituto Nacional de Pesquisas Espaciais (INPE), vinculado ao Ministério de Ciência e Tecnologia, a temporada de queimadas no Brasil (maio/junho a setembro/outubro), começou esse ano com um aumento na taxa de focos de incêndio no Pampa, Pantanal e Mata Atlântica. A Amazônia é o bioma que liderou o número de focos de incêndios, antes mesmo da estação de seca. No ano de 2020, foi registrado no Pantanal um aumento de $186 \%$ nos focos de incêndio em relação ao ano passado, já na Mata Atlântica, aumentou $44 \%$ no mesmo período. A prática da queimada é parte de um método para limpar o solo, que foi desmatado, para ser usado na pecuária ou agricultura. Também foi registrada falta de chuva nesses biomas, apontado como um dos fatores para o aumento do número de incêndios (OLIVEIRA, 2020).

Uma pesquisa recente da Datafolha (FOLHA DE SÃO PAULO, 2020) apurou a percepção dos brasileiros sobre o atual momento da floresta Amazônica. Segundo este estudo, quando o assunto é a floresta, o brasileiro está disposto a preservar e, em uma pontuação de 0 a 10, as respostas para determinadas perguntas foram: i) 9,8 quanto a importância da Amazônia para animais e biodiversidade; ii) 9,2 em relação a evitar o aquecimento do planeta; iii) 9,2 em evitar mudanças extremas no clima do planeta. Quanto a 
responsabilidade da preservação da Amazônia, $77 \%$ das pessoas acham que é dever do IBAMA e da FUNAI, 75\% acreditam ser obrigação do Ministro do Meio Ambiente (MMA), 75\% dos governos estaduais, $72 \%$ do Presidente da República e $66 \%$ do exército. Ainda $40 \%$ dos entrevistados consideraram o exército ótimo ou bom no combate ao desmatamento da Amazônia, 37\% aprovaram o trabalho do IBAMA e FUNAI, apenas $46 \%$ reprovaram a atuação do Presidente da República, 38\% acharam ruim ou péssimo o desempenho do Vice-presidente da República, 38\% reprovam o desemprenho do MMA e, ainda, $42 \%$ acharam ruim ou péssimo o trabalho dos governos estaduais. Quanto a responsabilidade da própria sociedade brasileira na destruição da floresta, $68 \%$ acreditaram que a população tem muita responsabilidade pelo combate ao desmatamento, $67 \%$ apontaram que os deputados e senadores também tem responsabilidade, $64 \%$ acreditam que seja responsabilidade das Organizações Não Governamentais (ONG's), 59\% acharam que o judiciário tem a incumbência pelo combate ao desmatamento e $56 \%$ acharam que esta obrigação é dos povos indígenas. Sendo, justamente os índios, que obtém melhor avaliação na luta pela preservação; $49 \%$ das pessoas acharam que os indígenas fazem um trabalho ótimo ou bom na defesa da floresta e 73\% acreditaram que o desmatamento aumentou em relação ao ano passado. Como culpados, $89 \%$ apontaram os madeireiros, $68 \%$ os garimpeiros, $67 \%$ os grandes fazendeiros e criadores de gado. Mais da metade dos entrevistados $(51 \%)$ acreditaram que a solução é multar e apreender os equipamentos dos responsáveis, bem como realizar mais reportagens e denúncias são importantes para combater a derrubada da floresta. Ainda, $60 \%$ disseram que a principal fonte de informação sobre Amazônia e meio ambiente é a televisão e somente 1 em cada 3 brasileiros acredita na ciência (33\%) (FANTÁSTICO, 2020).

Segundo Fearnside (2009), pesquisador do INPA, a maior parte das emissões de carbono do mundo é proveniente da queima de combustíveis fósseis, mas no Brasil, o desmatamento é a principal fonte. A floresta amazônica tem um papel fundamental na mitigação do aquecimento global por conta do seu grande estoque de carbono, tanto na biomassa quanto no solo. Se a floresta é desmatada, boa parte deste carbono é liberado na atmosfera em GEE (tais como gás carbônico e metano), também liberam carbono os incêndios florestais e a exploração madeireira.

De acordo com a Organização Meteorológica Mundial (OMM), agência especializada da ONU, que trabalha com comportamento da atmosfera da Terra, sua interação com os oceanos e clima; estimou que as emissões globais de carbono devem diminuir $6 \%$ neste ano, devido à queda nos lançamentos de GEE pelos setores de transportes, industrial e de produção de energia, devido a atual pandemia, ocasionada pelo novo coronavírus (Covid-19) (CNN BRASIL, 2020). Porém, conforme o SEEG (Sistema de Estimativas de Emissões de Gases de Efeito Estufa do Observatório do Clima), a tendência no Brasil é que em 2020, as emissões aumentem em relação ao ano anterior devido a principal fonte de emissão, que são as mudanças de uso da terra (responsável por $44 \%$ 
das emissões em 2018), estarem se expandindo pelo avanço do desmatamento na Amazônia, mesmo na pandemia. Em decorrência da pandemia, apesar de o Brasil tender a reduzir as emissões de GEE nos setores ligados a indústria, energia e resíduos, compensando ou deixando neutro o acréscimo das emissões do setor da pecuária, podem aumentar de $10 \%$ a $20 \%$ em relação a 2018 (último ano com dados disponíveis), devido ao desmatamento na Amazônia e da recuperação da economia (SEEG/OC, 2020).

A Representação da Organização Pan-Americana de Saúde (OPAS/OMS, 2009) no Brasil, em parceria com o Ministério da Saúde, por meio da Secretaria de Vigilância em Saúde, publicou em 2009, seu terceiro volume da série de publicações sobre Saúde Ambiental. O documento foi produzido pelo Departamento de Vigilância em Saúde Ambiental e Saúde do Trabalhador (DSAST) como referência para as discussões sobre os efeitos da mudança climática na saúde, nomeado "Mudança Climática e Saúde: Um perfil do Brasil". Apresenta as características das principais doenças e agravos influenciados pelo clima e suas futuras tendências, aspectos gerais das alterações climáticas junto de uma caracterização do Brasil, entre outras questões. As principais doenças que afetam a população brasileira, relacionadas as mudanças climáticas e seus condicionantes ambientais estão sumarizadas no Quadro 1.

Quadro 1: Principais doenças e seus condicionantes ambientais relacionados ao clima.

\begin{tabular}{|c|c|}
\hline PRINCIPAIS DOENCAS & CONDICIONANTES AMBIENTAIS \\
\hline 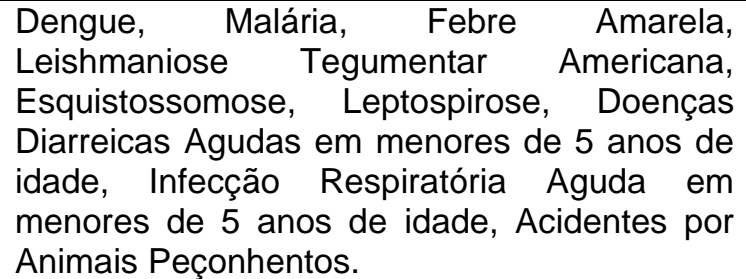 & $\begin{array}{l}\text { Aumento da temperatura, variabilidade da } \\
\text { precipitação, aumento de eventos extremos } \\
\text { que podem acarretar inundação ou seca, } \\
\text { qualidade do ar, queda da temperatura, ondas } \\
\text { de frio. }\end{array}$ \\
\hline
\end{tabular}

Fonte: Adaptado de OPAS/OMS (2009).

Além das consequências à saúde, os impactos das mudanças climáticas podem ter diversos efeitos, como alteração da disponibilidade de alimentos, podendo provocar subnutrição (gerando problemas no crescimento e desenvolvimento infantil); variações na quantidade e qualidade da água, fortalecendo a ocorrência de doenças diarreicas e doenças de veiculação hídrica (hepatites A e E), variação no comportamento dos episódios climáticos extremos, que podem alterar os perfis de morbimortalidade; além de refugiados ambientais e migrações, aumentando o risco de doenças emergentes e reemergentes (OPAS/OMS, 2009). No entanto, várias das principais doenças que afetam a população brasileira, como a asma e a bronquite pulmonar, também têm relação com as mudanças climáticas e seus condicionantes ambientais. 
De acordo com pesquisa realizada pelo IBOPE Inteligência (2018), 89\% dos brasileiros reconhecem a importância da educação para o desenvolvimento do Brasil. A população associa a violência e corrupção, dois dos grandes problemas do nosso país, com a pouca qualidade na educação. Também compreendem a recompensa da educação para o indivíduo, concebendo impactos positivos sobre a renda e empregabilidade. Contudo, a população brasileira acredita que, especialmente no ensino público, a qualidade da educação básica precisa melhorar. Nos últimos anos, aumentou a proporção das pessoas que avaliam a qualidade do ensino básico (em todos os níveis) como ruim ou péssima, sendo a pior avaliação mais registrada nas escolas públicas (CNI, 2018). Esta afirmação pode ser corroborada pelo presente trabalho, com as repostas dadas pelos alunos dos ensinos fundamental e médio, em que 36 e $50 \%$, dos alunos do ensino fundamental e médio, respectivamente, avaliaram como regular o grau de satisfação em relação a abordagem do tema na escola (Figura 4).

\section{$9^{\circ}$ ano do ensino fundamental $\quad 3^{\circ}$ ano do ensino médio}
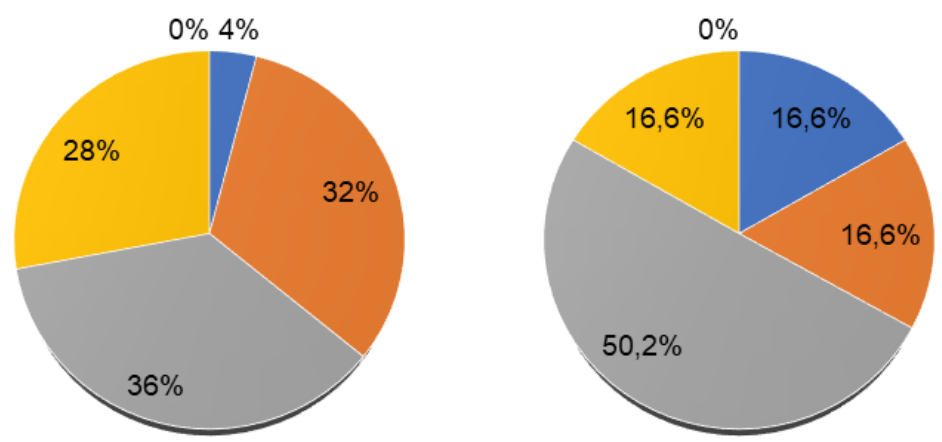

- muito insatisfeito | insatisfeito " regular " satisfeito " muito satisfeito

Figura 4: Grau de satisfação, em relação a abordagem sobre mudanças climáticas, nos últimos anos do Ensino Fundamenta e Ensino Médio.

Fonte: Elaborado pelos autores (2020).

Quando comparados aos alunos mais novos (ensino fundamental), o grau de satisfação dos estudantes do ensino médio, mostra-se ainda mais preocupante, pois metade deles consideram como regular aquilo que foi ensinado e poucos alunos mostram-se satisfeitos com aquilo que foi ofertado, sendo que nenhum aluno, de ambos os grupos, se mostrou muito satisfeito (Figura 4).

As lutas ecológicas no Brasil começaram a ganhar destaque na década de 70, com a idealização de ações, entidades e movimentos ecológicos e no plano governamental, com legislação e regulamentação para o controle do meio ambiente. A educação ambiental é parte do movimento ecológico, como um ato de conscientização capaz de alertar sobre os impactos negativos, sobre má distribuição no uso dos recursos naturais e como forma de atrair a 
população em ações socioambientais. Esta área vem se mostrando uma proposta pedagógica educativa com base na consciência da crise ambiental, que busca desenvolver uma perspectiva de compreensão as ações que afetam as relações entre os humanos e seu ambiente (CARVALHO, 2004).

Em relação as ações que os alunos julgam serem importantes para combater as mudanças climáticas e que acreditam que possam realizá-las em âmbito local, remetem principalmente a conscientização, preservação e atitudes governamentais, como leis e fiscalização, denúncia e atitudes responsáveis (Quadro 2).

Quadro 2: Ações que os alunos acreditam serem importantes para combater as mudanças climáticas.

\begin{tabular}{|c|c|c|}
\hline PERGUNTAS & RESPOSTAS $9^{\circ}$ ANO E. F & RESPOSTAS $3^{\circ}$ ANO E. M \\
\hline $\begin{array}{l}\text { Ações que julgam serem } \\
\text { importantes para conter as } \\
\text { mudanças climáticas em } \\
\text { âmbito de nação (Brasil) }\end{array}$ & $\begin{array}{l}\text { Reduzir as queimadas e } \\
\text { desmatamentos, mudança de } \\
\text { hábitos, utilizar a regra dos } \\
\text { 3R's, consumo consciente, } \\
\text { melhorar a fiscalização, mais } \\
\text { conscientização e respeito, } \\
\text { fornecer informação, punições } \\
\text { severas, economizar água e } \\
\text { plantar árvores. }\end{array}$ & \begin{tabular}{lr} 
Parar as & \multicolumn{2}{r}{ queimadas, } \\
preservação dos & biomas, \\
preservação do & meio \\
ambiente, não & desperdiçar \\
água, diminuir o consumo de \\
plástico, diminuir emissões de \\
gases tóxicos gerados por \\
usinas, ratitudes \\
governamentais, leis e \\
fiscalização.
\end{tabular} \\
\hline $\begin{array}{l}\text { Ações que julgam serem } \\
\text { importantes para conter as } \\
\text { mudanças climáticas em } \\
\text { âmbito local (município) }\end{array}$ & $\begin{array}{l}\text { Não poluir, conscientizar a } \\
\text { população, parar com as } \\
\text { queimadas, economizar água, } \\
\text { plantar árvores, não } \\
\text { desmatar. }\end{array}$ & $\begin{array}{l}\text { Economizar água, diminuir } \\
\text { fluxo de veículos, parar com } \\
\text { as queimadas, não cortar } \\
\text { árvores, multas e legislações } \\
\text { eficazes, fiscalização. }\end{array}$ \\
\hline $\begin{array}{l}\text { Ações que acreditam que } \\
\text { podem realizar } \\
\text { (individualmente ou } \\
\text { coletivamente) de forma local } \\
\text { (município) para evitar as } \\
\text { mudanças climáticas }\end{array}$ & $\begin{array}{l}\text { Não desmatar área urbana, } \\
\text { criação de áreas verdes, } \\
\text { reuso e reciclagem, manter o } \\
\text { município limpo, conversar } \\
\text { sobre o assunto com outras } \\
\text { pessoas, campanhas de } \\
\text { conscientização com a } \\
\text { população local, usar menos } \\
\text { os veículos e utilizar } \\
\text { transportes alternativos, como } \\
\text { bicicleta. }\end{array}$ & $\begin{array}{l}\text { Plantar árvores, usar menos } \\
\text { veículos, parar com as } \\
\text { queimadas em terrenos e } \\
\text { matas nativas, denúncias, } \\
\text { conscientização, naro náticas } \\
\text { contribuir com prí } \\
\text { negativas ao meio ambiente. }\end{array}$ \\
\hline
\end{tabular}

Fonte: Elaborado pelos autores (2020).

Em um aspecto geral, as respostas mais frequentes foram em relação a diminuição ou erradicação das queimadas e desmatamento. O consumo consciente, uma prática que é bastante comentada atualmente, mostrou-se recorrente. A falta de informação da população perante o cenário atual das mudanças climáticas e outros assuntos relacionados com o meio ambiente, foram mencionados por vários alunos. Estes sugeriram que a real importância de uma natureza equilibrada e sadia para nossas vidas deva ser explicado à 
população, assim como, suas consequências negativas, caso isso não seja alcançado. Outro tópico importante que foi apontado é a fiscalização e denúncia de práticas ilegais perante o meio ambiente, como o ato de atear fogo em terrenos abandonados ou em regiões de mata nativa.

Considerar o tempo é importante, quando relacionado a comportamentos pró-ambientais, como fazer as pessoas serem ambientalmente conscientes, pois em muitos casos o indivíduo tentará atuar de maneira individual e não pensará no coletivo. Mais tarde, essas ações gerarão problemas não para sua geração, mas para a de seus filhos e netos (MOSER, 1998). Portanto, fixar com mais frequência, que nossos atos perante o meio ambiente podem gerar impactos negativos, se realizados de maneira imprudente, provavelmente diminuirá o problema temporal.

A cidade avaliada, apresenta em sua Lei Orgânica (JABOTICABAL, 1990), um capítulo sobre meio ambiente, no qual incumbe ao Município: "promover a educação ambiental nos níveis de ensino de sua competência e conscientização pública para a preservação do meio ambiente". No ano de 2006, foi inaugurado um Centro de Educação Ambiental (CEA), considerado uma instalação modelo de sustentabilidade, que atende mais de dez requisitos do Programa Município Verde Azul. Porém, apesar da estrutura existente, a abordagem ambiental nas escolas se mostrou ainda insuficiente. Segundo De Oliveira et al. (2020), as escolas devem integrar em seus currículos a abordagem ambiental de uma maneira holística e transversal, perpassando por todos os componentes curriculares, consolidando as discussões e práticas que envolvam a temática em espaços educacionais formais, não-formais e informais devido a real possibilidade de escassez de recursos naturais que garantam a sobrevivência humana.

\section{Conclusões}

O presente trabalho mostrou que o nível de conhecimento em relação a temática do aquecimento global foi maior nos alunos de ensino médio. Ambos os grupos de alunos concordaram que o desmatamento é a maior fonte de emissão de GEE no Brasil e que este contribui para o aquecimento global. Destaca-se ainda, a preservação das florestas como essencial para a conservação dos processos biológicos e climáticos e segurança hídrica, energética e alimentar da nação. No entanto, surpreende o fato de mais da metade dos alunos de ambos os grupos desconhecerem os ODS da ONU, que são norteadores de ações, inclusive contra as mudanças climáticas.

$\mathrm{Na}$ avaliação dos alunos quanto ao grau de satisfação da abordagem do tema nas escolas, em ambas as séries, tanto da rede pública quanto da privada, a maioria dos alunos apontou como regular sua satisfação, sendo que a opção "muito satisfeito" não foi escolhida por nenhum aluno. Isso demonstra um cenário negativo e preocupante, tanto para a educação quanto para a mitigação das mudanças climáticas a nível local. Visto que, as escolas 
apresentam um papel fundamental na formação de cidadãos e abordar a problemática desse tema é essencial para se criar a sensibilização e conscientização da população sobre as questões ambientais.

As escolas são fundamentais para desenvolver conhecimento. Nesse espaço, os alunos entram em contato com várias experiências e saberes, desenvolvem um olhar crítico perante a realidade socioambiental e de como as mudanças devem ocorrer para que se alcance o desenvolvimento sustentável. Portanto, deve ser realizada uma maior abordagem do tema nas escolas, de modo a conscientizar a população sobre as questões ambientais, no que tange a sua própria qualidade de vida.

\section{Agradecimento}

À Faculdade de Tecnologia Nilo De Stéfani de Jaboticabal, pelo desenvolvimento do Trabalho de Graduação do curso de Gestão Ambiental.

\section{Referências}

ALVARES JUNIOR, O.M. Vehicle Technology and the Greenhouse Gases Emissions Control in Brazil. São Paulo, 2012. Disponível em: $<$ https://cetesb.sp.gov.br/proclima/2012/12/02/vehicle-technology-and-thegreenhouse-gases-emissions-control-in-brazil-2/>. Acesso em: 30 out. 2020.

BBC News Brasil. $O$ que são mudanças climáticas e outras 14 perguntas para entender o fenômeno. 2019. Disponível em: <https://www.bbc.com/portuguese/geral-50019998>. Acesso em: 21 abril 2021.

BOTH, F.; FISCHER, A. Gestão e contabilidade ambiental. Unoesc \& Ciência ACSA, Joaçaba, v.8, n.1, p. 49-57, 2017.

BRASIL. Constituição da República Federativa do Brasil. Brasília, DF: Presidência da República, 1988.

BRASIL. Decreto Legislativo no 144, de 20 de junho de 2002. Aprova o texto do Protocolo de Quioto à Convenção-Quadro das Nações Unidas sobre Mudança do Clima [...] Diário Oficial da União: seção 1, Brasília, DF, p. 2, 20 jun. 2002.

BRASIL. Lei no 12.187, de 29 de dezembro de 2009. Institui a Política Nacional sobre Mudança do Clima - PNMC. Disponível em: $<$ http://www.planalto.gov.br/ccivil 03/ ato2007-2010/2009/lei//12187.htm>.

Acesso em: 30 out. 2020.

CARVALHO, I. C. M. C. Outra ecologia é possível: a ecologia do movimento ecológico. In: CARVALHO, I. C. M. C. Educação ambiental: A formação do sujeito ecológico. S.Paulo: Cortez, 2004.

CERVO, A. L.; BERVIAN, P. A.; SILVA, R. Metodologia Científica. S.Paulo: Pearson Prentice Hall, 2007. 
CNI. CONFEDERAÇÃO NACIONAL DA INDÚSTRIA. Retratos da sociedade brasileira: Educação Básica, v. 7, n. 42, 2018.

CNN BRASIL. Em meio à pandemia, emissões de carbono devem cair $6 \%$ em 2020, diz OMM. São Paulo, 2020. Disponível em: $<$ https://www.cnnbrasil.com.br/saude/2020/04/22/em-meio-a-pandemiaemissoes-de-carbono-devem-cair-6-em-2020-diz-omn>. Acesso: 20 jul. 2020.

DE OLIVEIRA, A. N.; DE OLIVEIRA DOMINGOS, F.; COLASANTE, T. Reflexões sobre as práticas de educação ambiental em espaços de educação formal, não-formal e informal. Revista Brasileira De Educação Ambiental, v. 15, n. 7, p. 9-19, 2020.

ESCOBAR. H. Desmatamento da Amazônia dispara de novo em 2020. 2020. Disponível em: <https://jornal.usp.br/ciencias/desmatamento-daamazonia-dispara-de-novo-em-2020/>. Acesso em: 08 out. 2020.

FEARNSIDE, P. M. Mudanças climáticas globais e a floresta amazônica. In: BUCKERIDGE, M. S. Biologia e Mudanças Climáticas Globais no Brasil. S.Paulo: RiMa, 2008.

FEARNSIDE, P. M. O papel da Amazônia no combate ao aquecimento global. In: CONGRESSO BRASILEIRO DE FISIOLOGIA VEGETAL, XII. 2009, Fortaleza. Anais [...] Manaus: Instituto Nacional de Pesquisas da Amazônia (INPA), 2009.

FOLHA DE SÃO PAULO. Para 46\%, gestão de Bolsonaro em combate ao desmatamento na Amazônia é ruim ou péssima. Pesquisa Datafolha. 2020. Disponível em: <https://www1.folha.uol.com.br/cotidiano/2020/10/bolsonarotem-a-pior-avaliacao-no-brasil-em-combate-ao-desmatamento.shtml>. Acesso em: 02 nov. 2020.

FREIRE, P. Educação Como Prática da Liberdade. Rio de Janeiro: Paz e Terra, 1967.

GUERRA, A. F.; JACOBI, P.; SULAIMAN, S. N.; NEPOMUCENO, T. Mudanças climáticas, mudanças globais: desafios para a educação. Revista Eletrônica do Mestrado em Educação Ambiental, v. especial, 2010.

HODGES. J. Temperatura global sobe um grau Celsius e pode bater novo recorde. $2020 . \quad$ Disponível em: $<$ https://economia.uol.com.br/noticias/bloomberg/2020/01/30/aumento-datemperatura-global-pode-bater-novo-recorde.html>. Acesso em: 15 nov. 2020 IBOPE Inteligência. População reconhece que a educação básica no Brasil precisa melhorar. In: CNI. CONFEDERAÇÃO NACIONAL DA INDÚSTRIA. Retratos da sociedade brasileira: Educação Básica, v. 7, n.42, 2018.

IPCC. Intergovernmental Panel on Climate Change. Aquecimento Global de 1,5 $\mathbf{5}^{\circ}$ C. 2018.2 Disponível em: $<$ https://www.ipcc.ch/site/assets/uploads/2019/07/SPM-Portugueseversion.pdf $>$. Acesso em: 22 set. 2020. 
IPCC. Intergovernmental Panel on Climate Change. Report on the Ocean and Cryosphere in a Changing Climate. 2019. Disponível em: $<$ https://www.ipcc.ch/site/assets/uploads/sites/3/2019/11/03 SROCC SPM FIN AL.pdf>. Acesso em: 04 nov. 2020.

JABOTICABAL. Lei Orgânica Municipal $\mathbf{n}^{\circ} \mathbf{1}$, de 05 de abril de 1990. Disponível em: <https://www.jaboticabal.sp.leg.br/legislacao/lei-organica>. Acesso em: 03 nov. 2020.

LAWSON, D. F.; STEVENSON, K. T.; PETERSON, M. N.; CARRIER, S. J.; STRNAD, R. L.; SEEKAMP, E. Children can foster climate change concern among their parents. Nature Climate Change, v. 9, p. 458-462, 2019.

MCT - MINISTÉRIO DA CIÊNCIA E TECNOLOGIA. Protocolo de Quioto. Brasília, 2020.2 Disponível em: $<$ http://mudancasclimaticas.cptec.inpe.br/ rmclima/pdfs/Protocolo Quioto.pdf>. Acesso em: 04 nov. 2020.

MPF - MINISTÉRIO PÚBLICO FEFERAL. Acordo de Paris. Brasília, 2020. Disponível em: <http://www.mpf.mp.br/atuacao-tematica/sci/normaselegislacao/tratados/convencoes-meio-ambiente/acordo-de-paris.pdf/view>. Acesso em: 03 nov. 2020.

MOLION, L. C. B. Aquecimento Global: uma visão crítica. Revista Brasileira de Climatologia, v. 3, 2008.

MOSER, G. Psicologia Ambiental. Estudos de Psicologia, v. 3, n. 1, p.121130, 1998.

NOBRE, C. A. Mudanças climáticas globais: possíveis impactos nos ecossistemas do país. Parcerias Estratégicas, v. 6, n. 12, p. 239-258, 2001.

OBSERVATÓRIO DO CLIMA. Site institucional. Disponível em: $<$ http://www.observatoriodoclima.eco.br>. Acesso em: 02 de nov. de 2020.

OLIVEIRA. E. Temporada de queimadas começa com alta nos registros de incêndios no Pampa, Pantanal e Mata Atlântica. 2020. Disponível em: $<$ https://g1.globo.com/natureza/noticia/2020/06/02/temporada-de-queimadascomeca-com-alta-no-registros-de-incendios-no-pampa-pantanal-e-mataatlantica.ghtml>. Acesso em: 08 out. 2020.

ONU. Organização das Nações Unidas. Transformando Nosso Mundo: A Agenda 2030 para o Desenvolvimento Sustentável. 2015. Disponível em: <https://nacoesunidas.org/wp-content/uploads/2015/10/agenda2030-pt-br.pdf>. Acesso em: 02 dez. 2020.

OPAS/OMS. Mudança Climática e Saúde: um Perfil do Brasil. Brasília, 2009. Disponível em: $<$ https://www.paho.org/bra/index.php?option=com docman\&view=download\&ali as=431-mudanca-climatica-e-saude-um-perfil-do-brasil-

1 \&category slug=mudancas-climaticas-711\&ltemid=965> $>$. Acesso em: 01 out. 2020. 
PLATAFORMA AGENDA 2030. Agenda 2030. Disponível em: <http://www.agenda2030.org.br/>. Acesso em: 04 nov. 2020.

SECAD - Secretaria de Educação Continuada, Alfabetização e Diversidade, CADERNOS. Educação Ambiental: aprendizes de sustentabilidade. Brasília: MEC, 2007.

SEEG/OC. Impacto da pandemia de Covid-19 nas emissões de gases de efeito estufa no Brasil. 2020. Disponível em: <https://seegbr.s3.amazonaws.com/OC nota tecnica FINAL.pdf>. Acesso em: 17 out. 2020.

STECKEL, J. C. et al. Da carbonização à descarbonização? -Tendências anteriores e cenários futuros para as emissões de CO2 da China. Política Energética, v. 39, n. 6, p. 3443-3455, 2011.

VEISSID, N.; PEREIRA, E. B. Estimativa do albedo planetário empregando dados do experimento célula solar do satélite brasileiro SCD2. Revista Brasileira de Geofísica, v.18, n.1, 2000. 